\title{
La mercantilización de la educación durante la década neoliberal Argentina
}

\author{
María Claudia Cabrera*
}

Resumen: Este artículo presenta la discusión parlamentaria de la reforma del sistema educativo realizada en la Argentina durante década de 1990. El objetivo es analizar el modo como la ideología neoliberal se expresó en las políticas de gobierno, en este caso específicamente en la política educativa. Se considera que las ideologías construyen sentidos, modos de ver el mundo y tienen también un carácter material que se expresa en instituciones, normas, costumbres, etc. El análisis de la legislación educativa de la década permite así observar la transformación material de ciertos aspectos sociales a partir de la concepción ideológica del neoliberalismo que devino hegemónica.

Palabras clave: Neoliberalismo; hegemonía; ideología.

\section{The mercantilization of the education during the neoliberal decade Argentina}

\begin{abstract}
This article presents the parliamentary discussion of the reform of the educative system, made in Argentina during the decade of 1990. The objective is, specifically, to analyze the way that the neoliberal ideology was expressed in the government policies, in this case in the educative policy. It is considered that the ideologies construct senses; ways to see the world and also have a material character that is expressed in institutions, norms, customs, etc. The analysis of the educative legislation of the decade shows the material transformation of some social aspects, related with the ideological conception of the neoliberalism that became hegemonic.
\end{abstract}

Key words: neoliberalism, hegemony, ideology.

* Dr ${ }^{\mathrm{a}}$. en Ciencias Sociales (FLACSO Argentina); Docente de la Facultad de Ciencias Sociales, UBA. E-Mail: mccabrera@ymail.com

Latitude, Vol. 1, n², pp.99-118, 2007. 


\section{Introducción}

En este artículo se considerará el modo en que la ideología neoliberal se expresó como objetivo político de las políticas de gobierno en la Argentina durante la década de 1990. Se parte de la hipótesis según la cual las ideologías no son discursos más o menos conscientes, o falsa conciencia o una superestructura ideológica montada sobre una estructura material. Las ideologías construyen sentidos, modos de ver el mundo, que tienen también un carácter material que se expresa en instituciones, normas, costumbres, etc. ${ }^{1}$. Por ello se analizará legislación educativa de la década de 1990 dictada durante la presidencia de Carlos Menem² ${ }^{2}$ dado que permite observar la transformación material de ciertos aspectos sociales, para entender cómo se concibió la política social en general y la educativa en particular durante esa década, a partir de la concepción ideológica del neoliberalismo que devino hegemónica.

Respecto de la metodología, se tomará como objeto de análisis los objetivos políticos contenidos en los discursos de los legisladores pronunciados en los debates parlamentarios y en los textos de los proyectos en discusión, que dieron origen a leyes vinculadas con aspectos de lo social que fueron señalados por los propios economistas primero, y los políticos profesionales después, como propios de la intervención del Estado. Los datos para la investigación se construyeron a partir de fuentes documentales, por lo que el abordaje metodológico adecuado para ese objetivo implica el uso de técnicas cualitativas de análisis de documentos, así como una perspectiva teórica que permita captar las múltiples dimensiones del proceso en estudio.

Este artículo contiene tres apartados. El primero contiene algunos supuesto teóricos que enmarcan la reflexión sobre el proceso empírico que se analiza, que es desarrollado en el segundo aparado. Finalmente se presentan algunas reflexiones finales que funcionan a modo de conclusión.

\section{La sociedad de mercado del neoliberalismo}

Para el liberalismo económico los individuos constituyen la sociedad, y el papel del Estado debe limitarse a asegurar las condiciones de funcionamiento del libre mercado. Desde este análisis no hay, tal como postula la sociología, hechos sociales o estructuras objetivas coercitivas de ningún tipo por fuera de ellos; por el contrario, la sociedad de mercado se sostiene en una utopía antropológica: "la de un mundo moral

\footnotetext{
${ }^{1}$ Hechos sociales, como lo entiende la sociología de Durkheim.

${ }^{2}$ Carlos Menem asume a mediados de 1989 y es reelecto en 1995, terminando su segundo mandato en 1999.
}

Latitude, Vol. 1, n²2, pp.99-118, 2007. 
y social compuesto de puros individuos, absolutamente autónomos y soberanos amos de sí mismos" (ROSANVALLON, 2006, p. 13).

De este modo, toda regulación de las relaciones sociales se debería establecer a través de las normas impersonales del mercado, que se imponen por su propia racionalidad. Teóricamente no interfieren en ellas cuestiones subjetivas: simpatías o antipatías, prejuicios o afinidades. En este sentido el mercado tiene, siempre en términos teóricos, una gran capacidad de despersonalizar y por ello también de igualar a las personas ${ }^{3}$. Igualarlas en tanto compradores y vendedores en el mercado, y ello los convierte en definitiva en miembros útiles de la sociedad, o, en su defecto, inútiles, débiles o vulnerables.

Así, el liberalismo económico sostiene su estructura teórica e ideológica sobre esta afirmación respecto a que no hay más que individuos y que no existen estructuras objetivas por fuera de ellos. Este papel preponderante del individuo en la constitución del orden social conlleva un modo de entenderlo como racional y auto válido, que para satisfacer sus necesidades y hacerse con el mayor bienestar entra permanentemente en intercambio con otros en el mercado 4 . Para el liberalismo, las personas cuyo comportamiento es racional porque actúan en su propio beneficio -lo que incluye adaptarse a las condiciones y exigencias del mercado- son las que mejor se posicionan en él, mientras que quienes carecen de la disposición para esa adaptación, o de los recursos (capacitación, capital social, etc.) son los inadaptados o vulnerables que justifican las intervenciones del Estado a través de políticas represivas y/o sociales (algunas de las modalidades de intervenciones permitidas y convenientes del Estado). De este modo se preserva el mercado como lugar de no intervención, ya que ésta sólo será dirigida a aquellos que se excluyen (o autoexcluyen) del mercado (igualado a la sociedad).

En cuanto al Estado, el discurso clásico del liberalismo afirma que debe reducirse a su "mínima expresión", ya que no debería intervenir en la esfera de la economía (que es el espacio privilegiado de constitución de lazos sociales, por lo que la esfera de la economía no se limita a los intercambios en el mercado, sino que incorpora toda la sociedad). De este modo, el neoliberalismo en general ha aceptado una "utilidad" limitada del Estado y sus funciones específicas, que no puede delegar. De hecho, en la práctica esto ha producido un Estado activo y que se ha ocupado con firmeza de la implantación de políticas que procuraban asegurar las condiciones para el desarrollo del libre mercado, las que han significado una fuerte intervención en diversos órdenes de la sociedad, aunque discursivamente se siguió proclamando la importancia del "Estado mínimo". En definitiva el Estado ha tenido y tiene una

\footnotetext{
${ }^{3}$ Esta ideología requiere marginar la realidad para sostenerse, y esta afirmación es un claro ejemplo de ello.

${ }^{4}$ Desde este punto de vista, puede entenderse al mercado como un medio (el medio legítimo), y como el resultado de esos intercambios por necesidad e interés de los individuos.
}

Latitude, Vol. 1, n²2, pp.99-118, 2007. 
función fundamental: intervenir para garantizar el laissez-faire, pues como demuestra Polanyi (2003) "el laissez-faire no tenía nada de natural, los mercados libres no podrían haber surgido jamás con sólo permitir que las cosas tomaran su curso" (p. 194).

Esto se complementa con una concepción general dónde lo social y la política (que incluye al Estado) son entendidos como satélite del mercado, que es el sistema central que a su vez encierra toda la economía, y por lo tanto toda la sociedad (CABRERA, 2009). De este modo el mercado no sólo subordina en tanto secundariza y pone a los satélites al servicio de los "objetivos de mercado", sino que subsume las otras esferas de la sociedad, al convertirlas en sistemas satélites de un sistema constituido desde el mercado, invisibilizándolas. De este modo lo que existe es el mercado y la economía -o más correctamente relaciones mercantiles y económicas, ya que como señala Rosanvallon (2006), el liberalismo no reduce, sino que se amplía la sociedad a lo económico-.

La racionalidad del sistema central, que es la racionalidad del mercado autorregulado, se impone en los sistemas satélites, aunque en estos puede desarrollarse otras racionalidades, como la solidaridad en la sociedad civil ${ }^{5}$ o la equidad como principio que justifica la protección social que brinda el Estado, pero éstos siempre deben estar subordinados a la eficiencia del mercado. Y este fue el principio rector de la propuesta de transformación del sistema educativo.

\section{La educacion como cuestion economica}

Durante la década de 1990 se aprobaron tres leyes fundamentales que se proponían transformar el sistema educativo en conjunto. Y si bien puede discutirse la profundidad de esa transformación en la educación superior ${ }^{6}$, difícilmente pueda cuestionarse el éxito en cumplir ese objetivo en el resto del sistema.

La Ley de Transferencia de los Servicios Educativos, la Ley Federal de Educación y la Ley de Educación Superior se propusieron como objetivo la modificación de la educación en la Argentina en procura de lograr una mayor eficiencia en su implementación. El análisis se centrará en las dos primeras leyes, ya que ellas ponen en juego precisamente la concepción sobe el sistema educativo en conjunto, mientras que la Ley de Educación Superior tiene como objeto un sector más acotado de la comunidad educativa.

\footnotetext{
5 Podría decirse que esta visión solidarista de una sociedad civil "desinteresada", era la cara complementaria del liberalismo económico (GRASSI, 2003).

${ }^{6}$ No se pretende afirmar que la educación superior no sufriera transformaciones, pero no alcanzaron el nivel de las que se observaron en otros ámbitos educativos.
}

Latitude, Vol. 1, n²2, pp.99-118, 2007. 
La Ley de Transferencia Educativa, que llevó el número 24.049 tuvo su origen en un proyecto de la Senadora justicialista Olijela del Valle Rivas y el autonomista José Antonio Romero Feris. Fue tratada en el Senado el 13 y el 28 de noviembre de 1991, y pocos días después fue aprobada en la Cámara de Diputados, con un tratamiento sobre tablas, recurso reglamentario que permite eludir los plazos y pasos normales que debe cumplimentar un proyecto para su tratamiento.

Esta ley, aprobada en diciembre de 1991, registraba como antecedente parlamentario un proyecto enviado por el Poder Ejecutivo en febrero de 1990, que no recibió tratamiento en el recinto. En 1991 el Ejecutivo envió el proyecto de Presupuesto para el año 1992, que contenía entre sus puntos la transferencia de los servicios educativos.

Este proyecto fue desglosado, y tratado de manera separada, aunque el debate en la cámara de Diputados fue conjunto. Es decir, se trató la transferencia de los servicios educativos como tema inherente al Presupuesto, tratando éste a su vez, como un asunto meramente económico, olvidando que es básica y fundamentalmente una política de Estado. Se supone y presenta solamente como una cuestión económica cuando se elabora como una cuestión de caja desde el Ministerio de Economía, relegando la cuestión central de la planificación estratégica acerca de qué, dónde y cómo se decide invertir. Esto es y expresa una política. En el caso que se analiza no se economizó la educación por el hecho de haber sido tratada en conjunto con el Presupuesto, sino porque primero éste se había despolitizado. Es más, hubiera correspondido el tratamiento conjunto si se hubiera adoptado otro punto de vista: la definición explícita de prioridades políticas, que en este caso también se definían, aunque solapadas en un hecho contable.

El debate quedó así surcado por la tensión entre política educativa y económica, ya que la oposición remarcaba que desde su concepción esta ley fue pensada en términos economicistas, lo que explicaba que originariamente fuera concebida como parte del Presupuesto Nacional. E incluso se manifestaba una cierta resistencia del oficialismo al avance de esta perspectiva economicista, por lo menos en las formas, (ya que finalmente el contenido de estos proyectos fue votado por la mayoría en el recinto) observándose que desde el discurso de algunos legisladores del partido de gobierno o sus aliados se intentaba limitar esa impronta de las políticas propuestas. Esto se observa en el dictamen de Comisión (Orden del día ${ }^{7}$ [OD] 679/91) que aconseja aprobar el proyecto pero dónde se aclara que:

"Sin desconocer que la transferencia de servicios educativos nacionales está incluida en el marco de la reforma del Estado, que

\footnotetext{
${ }^{7}$ Documento legislativo dónde se publica el dictamen de las Comisiones, que puede incluir
} dictámenes en minoría.

Latitude, Vol. 1, n²2, pp.99-118, 2007. 
se fijó como meta el Poder Ejecutivo Nacional, consideramos necesario mantener la especificidad e identidad del espacio educativo en el ámbito de todas las áreas de gobierno. La transferencia de las escuelas es un hecho educativo. Por lo tanto, no corresponde que forme parte del articulado de una ley de presupuesto, pues ello sería considerar a la educación subordinada a las variables económicas." (OD 679/91)

Como se ha dicho, esta intención de la política de poner coto a la economía en los hechos terminaba muchas veces limitándose a una manifestación de principios sin efectos prácticos, ya que, como la misma Orden del Día expresa, el proyecto finalmente acepta la subordinación de la educación a "las variables económicas". Esto es claro cuando se observa, como lo hicieron notar legisladores de la oposición, que si bien proclamaba motivaciones vinculadas a lo educativo, no garantizaba el financiamiento para quienes debían asumir su implementación, dejando en manos del Poder Ejecutivo (y sus técnicos) la resolución de ese tema, señalando que "El capítulo cuarto propone los criterios más generales de financiamiento que luego deberán ser resueltos en la ley de presupuesto".

Durante el debate en el recinto, particularmente en el Senado, fueron pocos los senadores que cuestionaron el proyecto que, según insistía parte de la oposición, imponía un modo economicista de entender la educación. Por el contrario, en muchos casos tanto senadores opositores como oficialistas reconocían la necesidad de esta subordinación de la educación a la economía y la entendían como algo irremediable. En este sentido, pareció operar con eficacia la capacidad hegemónica del neoliberalismo de imponer los términos de los debates, de tal modo que aún muchos de quienes no pertenecían al oficialismo los aceptaban como indefectibles. Así lo expresaba el Senador por Corrientes Aguirre Lanari, del partido Liberal de Corrientes:

"Es evidente que el gobierno de la Nación está en tren de sacarle obligaciones al Estado nacional a los efectos de equilibrar el presupuesto, cosa que considero excelente. De esta manera se encauza nuestra economía por los rumbos que toda buena causa exige." (DSS ${ }^{8}$ 13/11/1991, p. 4046)

El Senador por Entre Ríos Ricardo Lafferriere, de la Unión Cívica Radical, remarcaba el costado economicista del proyecto, pero no sin reconocer que "la gran batalla que está librando el gobierno nacional -la que está librando el país- es la batalla económica." Por ello afirmaba que:

${ }^{8}$ DSS: Diario de Sesiones del Senado

Latitude, Vol. 1, n², pp.99-118, 2007. 
"No estamos poniendo palos en la rueda. No hemos obstaculizado ni restado quórum, prestando así nuestra solidaridad política ante la responsabilidad de los hombres que tienen que equilibrar la nave económica de la Argentina. Y aunque no nos guste, comprendemos que haya que poner el petróleo como bien de cambio, que haya que negociar el tema de los trenes, reformar el Estado con el tema de los teléfonos y Aerolíneas, o iniciar conversaciones respecto de otros asuntos." (DSS 13/11/1991, p. 4048)

Delimitados los términos de la discusión, Lafferriere aceptaba que la política económica escogida por el gobierno era un camino prácticamente ineludible, por lo que la oposición no podía hacer menos que allanar el camino para su implementación. Al mismo tiempo admitía la faceta económica de la política educativa (en los términos en que se planteaba el debate, se aceptaba que toda política tenía un aspecto económico cuya racionalidad primaba), y sólo criticaba que la discusión se diera en el marco de una coyuntura de urgencia fiscal:

“...en realidad cada vez más la discusión sobre la educación tiene un profundo contenido económico pero estratégico, un contenido económico del cual se deriva cual es el perfil de sociedad que podemos construir, un contenido económico que nos va diciendo si queremos hacer una sociedad con determinadas características o con otras."

"Lo cierto es que hoy estamos discutiendo este tema por una presión de coyuntura más que por una discusión estratégica, por el problema, en todo caso, de ver como nivelamos las cuentas." (DSS 13/11/1991, p. 4048)

Después agregaba:

"¿Qué es entonces lo que me preocupa de esta discusión económico educativa? Que en lugar de discutir la estrategia nacional para construir una sociedad igualitaria estemos analizando simplemente de qué manera podemos esquivar la presión de la coyuntura, sin preocuparnos demasiado por el verdadero tema de fondo. En estos momentos tendría que estar motivándonos la forma de encontrar un sistema científico tecnológico eficaz, cómo lo vinculamos con la

Latitude, Vol. 1, n²2, pp.99-118, 2007. 
producción, cómo hacemos una educación que esté arraigada en cada una de nuestras regiones." (DSS 13/11/1991, p. 4048)

En otro tramo de su discurso, este Senador relataba una anécdota que mostraba una vez más la tensión permanente entre "los técnicos" y "los políticos" durante esa década (esa tensión encontraba su punto más álgido en el interior del propio gobierno), que muchas veces -en general- significó la subordinación de los últimos a los primeros. Lafferriere relata:

"Días atrás, con la angustia que tenía por sentirme un poquito responsable -como todos nosotros- por la situación del país, le escribí una carta al Ministro de Economía en la que planteé esas angustias. Por supuesto, no me contestó; soy apenas un senador. Deshilvanadamente volqué en esa carta los conceptos que acabo de manifestar, y le escribí sobre el drama que sentía, que siento como senador - como seguramente sientes los 44 senadores restantes -; el drama, la impotencia por no poder influir como quisiera, de no poder influir en la estrategia nacional." (DSS 13/11/1991, p. 4049)

En la sesión del 28 de noviembre, cuando se aprobó la media sanción del proyecto, otro Senador radical (Adolfo Gass), representante de la provincia de Buenos Aires señalaba en el mismo sentido:

"Hemos discutido esto con el ministro Cavallo. El senador Trilla, a quien respeto por sus conocimientos en economía, ha hecho todos los esfuerzos posibles para encontrar una solución mejor. Inclusive fue a la reunión que se realizó en la Casa de Gobierno, a la que lamentablemente no dejaron entrar a los señores senadores." (DSS 2/11/1991, p. 4537)

Con estas palabras, Gass aceptaba como muchas veces se relegaba a los legisladores a un papel secundario en la definición de las políticas públicas, aún en aquellas que requerían la explícita aprobación de uno de los tres poderes del Estado: el legislativo, que desde la ideología general del neoliberalismo, debía limitar su papel al de refrendar las decisiones de un Poder Ejecutivo que a su vez debía responder a las políticas que proponían los "expertos", cuyas decisiones se fundaban en bases técnicas. En esas palabras de Gass sobrevolaba así una vez más la idea de inevitabilidad de la

Latitude, Vol. 1, n², pp.99-118, 2007. 
aceptación de la propuesta de "los técnicos", de un único camino posible. Tanto es así que en el marco de la discusión del proyecto, Gass reconocía que un gobernador electo (no menciona a quién se refiere específicamente) de su partido estuvo en la reunión " $y$ no se opuso a este proyecto de ley. Esto quiere decir que habrá interpretado que no había solución mejor y tuvo que asumirla..."

En la semana siguiente de la aprobación en la H. Cámara de Senadores, el proyecto recibió tratamiento en la Cámara de Diputados. En este recinto, el bloque justicialista presentó una moción a fin de tratar el proyecto de transferencia y el de presupuesto de manera conjunta. Al aprobarse la misma, servicios educativos y Presupuesto Nacional volvieron a ser un mismo asunto legislativo. El Diputado de Buenos Aires Juan Pablo Cafiero del peronismo disidente, procuró mostrar ese hecho como algo que no "va de suyo", remarcando la operación de transformación de la educación como propiedad social en política de mercado.

\begin{abstract}
"Este proyecto de ley no se inscribe en ese ámbito de descentralización sino en el del presupuesto. Por algún acuerdo hoy estamos tratando dos proyectos de ley diferentes: uno de presupuesto y otro de transferencia de servicios educativos, lo que es a todas luces una verdadera ficción. [...]....se sigue analizando la educación con el prisma y el microscopio de los objetivos fiscales. A la sombra de la palabra educación se siguen escribiendo ajuste fiscal, evasión, desigualdad, cumplimiento de las obligaciones con los organismos internacionales, en particular en las cartas de intención suscritas con el Fondo Monetario Internacional. En ellas se adelantó esta decisión del Estado no para descentralizar sino con ese argumento de sacarse de encima esta carga que se ubica al lado de los gastos de una embajada o de un consulado, como si la educación tuviera un valor puramente económico como los servicios públicos calificados de ineficientes, como los teléfonos o los servicios eléctricos. La idea es sacarse de encima las escuelas secundarias, las técnicas, las artísticas y los bachilleratos. La educación y la salud pasan a ser sujetos de las leyes de mercados, y antes que descentralizar el Estado se convierte en un desertor, en un fugitivo de sus obligaciones más importantes." (DSD 9 y 6/12/91, pp. 5326 - 5327)
\end{abstract}

Sin embargo los límites generales de discusión eran claros, y no se correspondían con los manifestados por el Diputado Juan Pablo Cafiero.

${ }^{9}$ DSD: Diario de Sesiones de la Cámara de Diputados

Latitude, Vol. 1, n²2, pp.99-118, 2007. 
Rafael Martinez Raymonda, Diputado demócrata progresista de la Capital Federal concedía que la desregulación era un supuesto inexorable en la definición de políticas públicas. En sus palabras "si deseamos construir un país que crezca, por supuesto debemos desregular" (DSD 5 y 6/12/91, p. 5332), aunque aclaraba que esa desregulación no incluía el poder de policía del Estado.

Jorge Gentile, justicialista de Córdoba expresaba sin ambigüedades la posición del gobierno, que era la de asumir la política pública no como una estrategia política, sino como un destino, una necesidad impuesta por las circunstancias, basada en una racionalidad técnica que imponía la economía. Por eso, este Diputado oficialista señalaba:

"El proyecto de ley de presupuesto y la transferencia de escuelas son instrumentos imprescindibles y necesarios, razón por la cual los vamos a votar afirmativamente en general, sin perjuicio de formular algunas críticas en particular." (DSD 5 y 6/12/91, p. 5335)

El proyecto fue finalmente convertido en ley y significó el puntapié inicial para la transformación del sistema educativo, que sería complementado después con otras dos leyes fundamentales: la Ley Federal de Educación y la Ley de Educación Superior.

La Ley Federal de Educación, que llevó el número 24.195, fue tratada por el Congreso Nacional durante el año 1992, y aprobada finalmente en abril de 1993, a un año del inicio del trámite legislativo. Durante el mismo, el proyecto fue considerado dos veces en cada Cámara, de acuerdo a lo que permitía la Constitución antes de su reforma en 1994.

El Diputado Ángel Elías, de la UCR de Santa Fe sintetizaba en su exposición los principios explícitos e implícitos de la política educativa que representaba el proyecto tratado, desde un discurso que buscaba marcar distancia de la hegemonía economicista:

"La recomposición que hace el neoconservadurismo en este estilo de política educativa coloca la centralidad de la responsabilidad por el desarrollo de la educación en las personas, las familias, las instituciones menores y las confesiones religiosas."

"Más allá de que existen distintas tendencias, siempre aparecen tres características o denominadores comunes en las políticas neoconservadoras en materia educativa, y las tres surgen en este

Latitude, Vol. 1, n²2, pp.99-118, 2007. 
proyecto que hoy se va a aprobar. En primer lugar siempre se va a poner de manifiesto que el desarrollo del sistema público de educación es perjudicial, en segundo término se puntualiza que el presupuesto público debe subsidiar al sector privado, y por último, se plantea la reducción del gasto destinado al sistema de educación pública."

"Este es un proyecto que se ubica en esa concepción general. Su objetivo principal no se centra en plantear la estructura $y$ composición del sistema educativo en su conjunto, ya que ello aparece como materia tangencial en su normativa. Si leemos con detenimiento, parece que se busca sellar una relación entre lo público y lo privado, lo cual guarda relación con la legislación sobre transferencia de escuelas nacionales a las provincias." (DSD 14/4/93, p. 6773)

Este proyecto de ley, de marcado tinte neoconservador según las palabras del Diputado Elías, involucró además el tratamiento de otros temas altamente conflictivos y controversiales. Así cuestiones como el papel de la familia en la educación, la educación privada y la cuestión confesional aparecen definiendo ejes del debate, acompañados de otros de menor importancia en la discusión: la cuestión indígena, cuestiones de género (y la utilización del masculino genérico o la expresa aclaración de los as/os en cada caso), e incluso la utilización de la palabra Latinoamérica (que según un Senador era originariamente un término despectivo y discriminatorio inventado por intelectuales franceses). Como hacía notar el Diputado Elías, esta jerarquía en la importancia de los temas que involucra la educación señala las cuestiones que desde la concepción neoliberal son las propias de la educación: familia, instituciones y confesiones religiosas.

Si bien los aspectos economicistas del proyecto fueron señalados por algunos legisladores opositores, estas manifestaciones eran minoritarias y no alcanzaron a imponer una línea de debate significativa. Sin embargo, en un momento de la larga discusión de esta ley se produjo un debate sobre políticas sociales en educación, que permite un acercamiento a los términos que dominaban las argumentaciones sobre este tema.

En ese debate algunas posiciones sostenidas por la U.Ce.De., partido político que históricamente representó el pensamiento liberal de nuestro país, se vuelven significativas al explicitar lo que los políticos más tradicionales del oficialismo no podían o no se atrevían. La U.Ce.De. se había convertido en un importante aliado del

Latitude, Vol. 1, n², pp.99-118, 2007. 
gobierno de Menem $^{10}$, y muchos de sus dirigentes asumieron puestos en el gobierno, convirtiéndose la hija de Álvaro Alsogaray, María Julia, en una figura emblemática de esta alianza. Los legisladores de este partido de derecha que no estaban comprometidos con el discurso tradicional del peronismo, pudieron expresar con mayor trasparencia los objetivos de esta ley, sin necesidad de apelar a eufemismos que los hicieran aceptables para la militancia del partido que encabezaba el gobierno.

El discurso de los diputados ucedeistas trasladó de manera literal y directa ${ }^{11}$ los principios establecidos por los economistas (de ideología neoliberal) en materia de políticas públicas y en particular en el área de la educación. En la sesión del 1 y 2 de septiembre de 1992 el Diputado García Cuerva representante de la provincia de Buenos Aires señalaba el principal responsable de los problemas que acuciaban al sistema educativo: la burocracia.

"Es evidente que quedaremos en manos de la burocracia con respecto a la reglamentación de la ley. Atención que aquí no hablo de un específico interés del Poder ejecutivo en cuanto a la implementación de esta norma, sino de la burocracia de ayer y de antes de ayer, que todavía subsiste transitando por los pasillos de los ministerios. Esa burocracia es en gran medida la responsable del estado en que se encuentra el sistema educativo de la República Argentina en este momento." (DSD 1 y 2/9/1992, p. 2318)

Estos burócratas, a diferencia de los "técnicos", representaban el viejo Estado, eran "sectores enquistados en todos los gobiernos", incapaces de implementar las políticas que el Estado definía. Cabe recordar que en la concepción neoliberal, el actor privado era el más capacitado para ello, aunque en la práctica se seguían las prescripciones de los organismos internacionales de crédito. Estos señalaban que en procura de profesionalizar el modo en que se implementaban las políticas públicas se debía recurrir a consultores profesionales, que eran contratados por los organismos estatales, duplicando finalmente la estructura burocrática del Estado, a la vez que precarizaban sus condiciones de trabajo ${ }^{12}$.

${ }^{10}$ Sin embargo, esto no fue fácil de aceptar para muchos de los dirigentes y funcionarios justicialistas, que procuraron "disimular" esta alianza, que se oponía a todo el discurso histórico del peronismo.

11 Considerando las mediaciones habituales de los políticos frente a la crudeza de los economistas, quienes, amparados en la ciencia, desdeñaban el populismo de la política.

12 Precarizaban desde el lado de las protecciones, al implementar la modalidad de contrato a tiempo determinado, que generalmente funcionaba con mecanismos de renovación automática, pero que siempre era una espada de Damocles sobre la estabilidad de los trabajadores. Pero

Latitude, Vol. 1, n²2, pp.99-118, 2007. 
Álvaro Alsogaray ${ }^{13}$, fundador de la U.Ce.De, funcionario de varios gobiernos democráticos y de facto y a la sazón Diputado por la U.Ce.De. dio un corto pero encendido discurso, dónde puso en blanco sobre negro los objetivos del proyecto que se presentaba, dejando en claro los principios ideológicos sobre los que se discutía.

Alsogaray sostenía en su discurso que existían sólo dos modelos posibles de país: "el socialista y el liberal; no hay otros. Si alguien piensa que existe otro modelo tendría que señalarlo porque seguramente nos llevaría a un debate interesante, tal como se está realizando en otras partes del mundo" (DSD 1 y 2/9/92, p. 2322). En esa disyuntiva no había opciones posibles. Y si bien el proyecto no era todo lo liberal que Alsogaray hubiera deseado, la "tendencia liberal" que mostraba era suficiente para contar con su apoyo.

Acorde a las concepciones que había sostenido durante toda su vida pública, afirmaba que "habríamos podido dictar una ley mucho más breve si hubiéramos establecido los principios fundamentales, dejando para otros niveles su instrumentación" (DSD 1 y 2/9/92, p. 2323). Así, si el Estado se hubiera limitado a asumir sólo sus funciones específicas (definición de políticas), se hubiera agilizado el largo trámite de la ley.

De este modo Alsogaray se convertía en un vocero de los argumentos ideológicos, más que económicos, del neoliberalismo. Puede decirse que desde su concepción la sociedad era de un conjunto de individuos y familias que sabían cuáles eran sus intereses y necesidades. El Estado debía ser simplemente el gobierno de esos intereses, asumiendo funciones de coordinación, y limitándose sólo a ello. Por eso un tema central mencionado por Alsogaray era, por ejemplo, definir quien tenía "la principalidad de la enseñanza. ¿Es el Estado o la familia?" (DSD 1 y 2/9/92, p. 2323), y la respuesta a esta pregunta era, por supuesto, la familia, ya que "el Estado debe actuar como control y vigilancia, y subsidiariamente, cuando los otros organismos no están en condiciones de intervenir en la ejecución directa" (DSD 1 y 2/9/92, p. 2323). Otro tema fundamental a definir, según este Diputado, era la cuestión de la gratuidad de la enseñanza, y sus reflexiones mostraban las concepciones del liberalismo tradicional sobre el punto:

también la relación precarizaba al otro componente del lazo social: el del reconocimiento. Esta política de flexibilización del empleo público terminó por desjerarquizar el trabajo de la planta permanente, provocando un gran malestar y sufrimiento entre esos trabajadores.

13 Alvaro Alsogaray representa el tipo ideal de intelectual liberal tradicional. Con 60 años en 1983, provenía de una familia tradicional argentina. De formación militar, se recibió como ingeniero mecánico aeronáutico de la Universidad de Córdoba, y no contaba con formación académica en economía. Participó de diversos partidos de cuño liberal, y de la gestión de gobiernos tanto militares como civiles. A pesar de representar lo más álgido del anti peronismo nacional, durante el gobierno de Menem fue Diputado Nacional y Asesor Presidencial con rango de Secretario de Estado (Beltrán, 2005).

Latitude, Vol. 1, n², pp.99-118, 2007. 
"Se ha insistido mucho en que la enseñanza debe ser gratuita; y eso no existe. La enseñanza cuesta caro: hay que pagar profesores, maestros, gabinetes, edificios, etcétera. Esto de la enseñanza gratuita es un eufemismo. [...] Lo que se está discutiendo en realidad es quién paga y quién recibe algo gratis."

"No existen las cosas gratis en la naturaleza, a menos que se espere que caiga algo de un árbol. La enseñanza no es gratuita; es muy cara. Sólo cabe determinar quién paga y quién recibe algo que no le cuesta ningún esfuerzo." (DSD 1 y 2/9/92, p. 2323)

Sentados los principios económicos con que la educación debía ser analizada, el Diputado Alsogaray reconocía que, de todos modos, se debía asegurar que nadie con la capacidad necesaria para estudiar debiera dejar sus estudios en cualquier nivel por razones económicas. Para ello debían existir las becas, de modo tal que:

"Si [la persona] tiene algo dentro del cerebro y puede educarse, se beneficia él y beneficia a la sociedad. Por ello la sociedad debe proveer a esta situación por medio del otorgamiento de becas, pero en forma selectiva." (DSD 1 y 2/9/92, p. 2323)

Ante este discurso de neto corte neoliberal, la mayoría justicialista quedó en la incómoda posición de avalar con su silencio ${ }^{14}$.

Durante el debate en particular merece especial atención la discusión del título VIII "Gratuidad y Asistencia" ${ }^{15}$ que comprendía los artículos 44 y 45 . En estos artículos se desplegaba la normativa referida a las garantías que brindaba el Estado acerca del acceso a la educación, y justifica la larga cita, dado que permite analizar el modo en que lo social era abordado desde el concepto rector de equidad:

"Art. 44- El Estado nacional y las jurisdicciones educativas se obligan, mediante la asignación del presupuesto educativo de la Nación y de las distintas jurisdicciones, a garantizar el principio de gratuidad en los servicios estatales, en todos los niveles $y$ modalidades."

\footnotetext{
14 “Creo que los legisladores peronistas no se tienen por qué sonrojar, porque lo que acabo de decir es un verdadero mérito." (DSD 1 y 2/9/92:2322) espetó el Ingeniero Alsogaray.

${ }^{15}$ Finalmente aprobado como Título VI (arts. 39 y 40) con modificaciones.
}

Latitude, Vol. 1, n²2, pp.99-118, 2007. 
"El Estado nacional realizará el aporte financiero principal al sistema universitario estatal para asegurar que ese servicio se preste a todos los habitantes que lo requieran. Las universidades podrán disponer de otras fuentes complementarias de financiamiento que serán establecidas por una ley específica, sobre la base de los principios de gratuidad y equidad..."

"El Estado nacional y las jurisdicciones educativas establecerán un sistema de becas para alumnos/as en condiciones socioeconómicas desfavorables, que cursen ciclos y/o niveles posteriores a la educación general básica, las que se basarán en el rendimiento académico."

“Art. 45 - El Estado nacional y las jurisdicciones se obligan a:

a) Garantizar a todos los alumnos/as el cumplimiento de la obligatoriedad que determina la presente ley, ampliando la oferta de servicios e implementando, con criterio solidario, en concertación con los organismos de acción social estatales y privados, cooperadoras, cooperativas y otras asociaciones intermedias, programas asistenciales de salud, alimentación, vestido, material de estudio y transporte para los niños/as y adolescentes de los sectores sociales más desfavorecidos. En todos los casos los organismos estatales integraran sus esfuerzos, a fin de lograr la optimización de los recursos, y se adoptarán acciones específicas para las personas que no ingresen al sistema, para las que abandonan y para las repitentes;

b) Organizar planes asistenciales específicos para los niños/as atendidos por la educación inicial pertenecientes a familias con necesidades básicas insatisfechas, en concertación con organismos de acción social estatales y privados;

c) Organizar planes asistenciales específicos para los niños/ as atendidos por la educación especial pertenecientes a familias con necesidades básicas insatisfechas desde la etapa de estimulación temprana, en concertación con los organismos estatales y privados que correspondan.

Los planes y programas de salud y alimentación que se desarrollen en el ámbito escolar estarán orientados al conjunto de los alumnos/ as."

Latitude, Vol. 1, n², pp.99-118, 2007. 
El primer párrafo del artículo 44 puede ser interpretado como el resultado de la tensión entre la racionalidad económica y la política: era impensable que un gobierno peronista no declamara una garantía de la gratuidad en una ley que proponía una reforma en el sistema educativo de esta magnitud. Sin embargo, al final del párrafo siguiente se abre la puerta al arancelamiento universitario. Del mismo modo, como se señaló repetidamente en el debate, no se aclaraba de qué modo se garantizaría esa gratuidad, ya que el financiamiento del sistema educativo quedaba en manos de los "técnicos" encargados de elaborar el presupuesto nacional.

Ángela Sureda, diputada de Santa Cruz por la UCR intentó proponer una alternativa a lo que se presentaba como la única alternativa posible, al defender el proyecto sobre educación presentado por ese partido político y que se encontraba contenido en la Orden del Día 613/92 como dictamen de minoría. Comparando ambos señalaba: "la asistencialidad debe ser integral para los alumnos y agentes de
los servicios de educación formal a cargo del Estado, es decir que no
hacemos una distinción como la que sí se desprende del proyecto en
consideración. Por ejemplo, su artículo 45 se refiere a los sectores
sociales más desfavorecidos; pero nosotros consideramos que
incluso un niño que no pertenezca a ese sector en un determinado
momento puede necesitar la asistencialidad del Estado. [...]
Nosotros tenemos en cuenta las necesidades del educando sin
considerar el sector social al que pertenece." (DSD 2 y 3/9/92, p.
2418 )

La respuesta estuvo a cargo del Diputado justicialista por la provincia de Buenos Aires, Eduardo Amadeo, quién como ya se ha mencionado, entre 1994 y 1998 fue Secretario de Desarrollo Social del gobierno nacional.

\footnotetext{
"Todas las estadísticas demuestran -incluso el sentido comúnque un efecto negativo de las políticas sociales lo constituye su falta de direccionalidad: esto es, los que pueden pagar la clínica privada y van al hospital público porque es mejor; los que no pagan los créditos del Estado; los que reciben cajas de alimentos que no necesitan, etcétera."

"Las estadísticas son absolutamente objetivas. Hablan de cientos de millones de pesos que se han perdido en el pasado al no haber sido otorgados a quienes más lo necesitaban. [...] El énfasis que pusimos sobre este tema en la discusión en comisión y el que me
}

Latitude, Vol. 1, n², pp.99-118, 2007. 
permito expresar en este momento se debe a nuestro deseo de defender el principio de focalización de las políticas sociales. Si la falta de focalización era irracional en épocas de inflación, cuando el dinero fluía de la maquinita, hoy, cuando el Estado tiene limitadas posibilidades de financiamiento, constituye un crimen de lesa patria que afecta a los más pobres." (DSD 2 y 3/9/92, p. 2419)

Y específicamente con referencia al principio de equidad agregaba "Utilizamos una palabra que nos quieren hacer suprimir: equidad. No puede haber justicia social sin equidad, y ésta no significa que todos reciban lo mismo sino que más reciban los que más necesitan". (DSD 2 y 3/9/92:2420)

En el mismo sentido el Diputado Mario Verdú, del partido Demócrata Progresista de Santa Fe añadía que "el Estado tiene cuatro funciones esenciales: educación, salud, seguridad y asistencialidad. [...] El Poder Ejecutivo deberá determinar una política en materia de becas para ayudar a los más capaces y más necesitados, abandonando el exceso de reglamentarismo". (DSD 2 y 3/9/92, p. 2420)

Por su parte, el Diputado de San Juan Luis Alberto Martínez, del Frente Justicialista, proponía en su exposición que la distribución de los fondos de asistencia se hiciera en base a la necesidad de la eficiencia, que no era otra cosa que la focalización de la asistencia:

"Resulta difícil encontrar una redacción que garantice de manera
absoluta que los fondos destinados a asistencialidad lleguen
exactamente al lugar determinado sin ningún tipo de desviaciones.
La única garantía con la que contamos es la realidad objetiva que
tienen a mano los responsables de la prestación del servicio
educativo. Serán las respectivas jurisdicciones, en cuyas manos
estarán la administración y conducción de las escuelas, las que
podrán calificar o cualificar la condición socioeconómica en la que
está inserta la escuela. Seguramente una escuela de Martínez no
obtendrá la misma calificación que un establecimiento de la villa La
Cava en los suburbios del conurbano bonaerense."
"Debemos confiar en la consolidación de aquel principio que de que
la asistencialidad debe privilegiar a los sectores más necesitados.
Una vez garantizada la voluntad del legislador debemos confiar en
que quienes harán efectiva... (Interrupción)"
"Para mi es importante la voluntad política expresada por todos los
sectores aquí representados en el sentido que debemos orientar la

Latitude, Vol. 1, n², pp.99-118, 2007. 
asistencialidad para que llegue a quienes más la necesitan. [...] Difíilmente podemos encontrar la fórmula que llegue directamente a donde queremos que llegue y que elimine a otras. Esto lo hará la sapiencia, la sensibilidad, la conducta de los actores de la sociedad que participen, en este caso, del sistema educativo conforme sus responsabilidades." (DSD 2 y 3/9/92, p. 2422)

Estos proyectos convertidos en ley significaron una transformación del sistema educativo, pero también una naturalización del economicismo como criterio del diseño de políticas en el área, mercantilizando la concepción misma de la educación como derecho.

\section{Reflexiones finales}

Los lineamientos fundamentales del pensamiento neoliberal señalaban que el Estado debía definir políticas pero que debían ser los particulares quienes las implementaran. Una de las políticas que al Estado le correspondía definir era la vinculada con la educación, entendida en términos de mercado. Por ello los problemas y cuestiones que se planteaba en torno a ella eran cuestiones que podían ser resueltas técnicamente por los economistas. Incluso los políticos debían aceptar esta premisa, definiendo las políticas en general, pero aceptando que debían hacerlo bajo la premisa de la "racionalidad de mercado".

Así, se proponían medidas políticas tendientes a generar el contexto que asegurara al mercado las condiciones de su autorregulación. Así, la racionalización de los gastos del Estado, cuyos objetivos debían ser claramente delimitados, era congruente con un aparato burocrático mínimo, indispensable para asegurar su funcionamiento (lo que no es necesariamente "Estado débil" o no interventor). Desde la racionalidad de la oferta y la demanda, los objetivos del sistema deberían corresponderse con los recursos, y siguiendo la misma lógica, era el mercado el que debía asignar los recursos que determinarían la viabilidad de los objetivos propuestos.

Debía asegurarse una organización (económicamente) racional del sistema, pero sin olvidar que debía reservarse una participación del Estado, particularmente para asegurar la financiación de la cobertura de "la población desprotegida", bajo el principio de equidad y solidaridad por el cual el Estado debía garantizar el funcionamiento de mecanismos de protección social pero sin abandonar por ello los principios de racionalidad y eficiencia que provenían del mercado. De este modo, el Estado subsanaría las "fallas del mercado" una de cuyas consecuencia podría ser que parte de la población de sujetos débiles no tuviera acceso al sistema de educativo, por

Latitude, Vol. 1, n², pp.99-118, 2007. 
lo que, en nombre de principios de equidad, se debía asegurar el ingreso de esa población si demostraba merecerlo (es decir, como señalaba el Diputado Alsogaray, si tenían algo en el cerebro). Así, la asistencia a la población de débiles/inútiles/incapaces no se presentaba como un problema que sobrepasase los aspectos referidos a la implementación de la ayuda y la racionalidad de su organización.

La promoción de la equidad fue presentada como una obligación fundamental del Estado, ya que permitía a los más débiles acceder a una "igualdad de oportunidades $^{16}$. La equidad aparecía con frecuencia asociada a la eficiencia y era el sistema vigente (ineficiente) el que impedía su desarrollo y/o aumento. Si se lograba superar los escollos de la ineficiencia se obtendría como resultado una mayor equidad en la sociedad.

La equidad como principio, teniendo por sujetos a los individuos, permitía el desarrollo de mecanismos que intervinieran en procura de subsanar situaciones específicas. Cuando estos mecanismos (que en general se realizan como políticas sociales) son correctamente implementados deberían ser eficientes. La focalización en individuos o poblaciones específicas permitiría dirigir los recursos de manera certera y sin dispersiones, es decir, eficiente. En ese sentido, los proyectos que involucran políticas sociales se sustentaban en la equidad y la eficiencia de manera asociada, por lo que la asistencia directa y focalizada era el modo de implementación que mejor se adaptaba a estos principios.

\section{Bibliografía}

BELTRAN, G. Los intelectuales liberales: poder tradicional y poder programático en la Argentina reciente. Buenos Aires: EUDEBA; 2005.

CASTEL R. Las metamorfosis de la cuestión social. Una crónica del salariado. Buenos Aires: Paidós; 1997.

CABRERA MC. La cuestión social como cuestión económica en la producción especializada de los principales thinks tanks de la argentina. Su papel intelectual y político en la orientación y fundamentación de políticas sociales durante la hegemonía neoliberal. Buenos Aires. 271 páginas. Tesis de doctorado presentada en FLACSO; 2009.

GRASSI E. Políticas y problemas sociales en la sociedad neoliberal. La otra década infame. Vol I. Buenos Aires: Espacio; 2003.

ROSANVALLON P. El capitalismo utópico. Buenos Aires: Nueva visión; 2006.

\footnotetext{
${ }^{16}$ La igualdad, entendida en el sentido de "igual para todos" no se planteó como un problema para la política de aquellos años.
}

Latitude, Vol. 1, n²2, pp.99-118, 2007. 
ROSANVALLON P. La Nueva Cuestión Social. Repensar el estado providencia. Buenos Aires: Manantial; 1995.

\section{Fuentes}

REPÚBLICA ARGENTINA. H. Cámara de Senadores de la Nación. (1993) Diario de Sesiones. 22 y 23/9/93, 3306 - 3405. Buenos Aires: Imprenta del Congreso de la Nación

REPÚBLICA ARGENTINA. H. Cámara de Diputados de la Nación. (1993) Diario de Sesiones. 29 y 30/4/93, 7011 - 7136. Buenos Aires: Imprenta del Congreso de la Nación.

REPÚBLICA ARGENTINA. H. Cámara de Diputados de la Nación. (1993) Diario de Sesiones. 28 y 29/4/93, 6830 - 6993. Buenos Aires: Imprenta del Congreso de la Nación.

REPÚBLICA ARGENTINA. H. Cámara de Diputados de la Nación. (1993) Diario de Sesiones. 5 y 6/5/93, 247 - 323. Buenos Aires: Imprenta del Congreso de la Nación.

REPÚBLICA ARGENTINA. H. Cámara de Senadores de la Nación. (1993) Diario de Sesiones. 22 y 23/9/93, 3306 - 3405. Buenos Aires: Imprenta del Congreso de la Nación.

REPÚBLICA ARGENTINA. H. Cámara de Diputados de la Nación. (1992) Orden del día 922/92. Buenos Aires: Imprenta del Congreso de la Nación.

Latitude, Vol. 1, n²2, pp.99-118, 2007. 